\title{
Pesca artesanal en el Perú
}

\author{
Jorge Amadeo Medicina Di Paolo \\ Universidad de Lima. Lima, Perú \\ Correo electrónico: Jmedicin@ulima.edu.pe
}

Recibido: 22 de mayo de 2014 / Aprobado: 11 de julio de 2014

Resumen: El objetivo del artículo es dar a conocer el comportamiento de la pesca marítima de tipo artesanal en el Perú y sus repercusiones en el valor bruto de la producción local; asimismo, se busca demostrar la debilidad del sector debido a su baja productividad a causa de la informalidad de gran escala que se presenta en el subsector destinado al consumo humano directo. A pesar de las elevadas tasas de crecimiento del PBI real en los últimos siete años, el subsector pesca no ha podido crecer en promedio por encima del $12 \%$. La escasa infraestructura para la captura, almacenamiento, conservación en frío, el reducido financiamiento para los bienes de capital en equipamiento y aparejos requeridos para cada embarcación del tipo artesanal, así como el bajo grado de instrucción de las personas dedicadas a esta actividad, hacen que el sector muy vulnerable y de baja competitividad.

Palabras clave: productividad / informalidad / crecimiento sostenido / competitividad / recursos / infraestructura / aparejos

\section{Artisanal fishing in Peru}

Abstract: The purpose of the article is to understand the behavior of artisanal marine fisheries in Peru and its impact on the gross value of local production, demonstrating the weakness of the sector by low productivity due to the informality of scale presented subsector for direct human consumer. In spite of the high growth rates of real GDP in the last seven years, the fisheries subsector unable to grow on average by over $12 \%$. Poor infrastructure for the collection, storage, cold storage, reduced funding for capital goods and equipment required for each boat rigging of craft type and the low level of education of people engaged in this activity, make the sector very vulnerable and low competitiveness.

Key words: productivity / informality / sustained growth / competitiveness / resources / infrastructure / tackle 


\section{INTRODUCCIÓN}

El propósito del artículo es facilitar al lector la ruta para estudiar y conocer de manera secuencial el comportamiento del subsector pesca en el Perú y cómo es que interactúan los agentes productores, acopiadores y consumidores frente a un entorno político, económico y social poco o nada favorable para el mercado de los productos hidrobiológicos marinos dirigido al consumo humano directo. El desembarque de la pesca marítima de tipo artesanal (hoy también llamada pesca de menor escala) se desarrolla de manera casi informal e ineluctablemente se crean reglas extralegales, lo que hace aún más difícil salir del círculo de pobreza en el cual se encuentran miles de personas ${ }^{1}$ que trabajan con una reducida productividad, lo que resta la competitividad en toda la cadena de valor y afecta el crecimiento sostenido del subsector.

El subsector pesca está compuesto por la pesca marítima, la pesca continental y la pesca de acuicultura. A su vez, la primera se subdivide en industrial y artesanal. En la segunda, la continental, se encuentra el tipo extractivo ornamental; por último, en la acuicultura se halla la pesca marítima y la de tipo continental.

En la primera parte del artículo, se conocerá el significado de la pesca artesanal o pesca de menor escala en el Perú. Asimismo, se describirán las características de las embarcaciones, aparejos utilizados en los diferentes tipos de pesca para el consumo humano directo, la tecnología empleada, el perfil del tripulante-pescador, el estilo de vida y el accionar de la pesca artesanal, donde se comprueba que no existe una normatividad adecuada para la captura de especies bajo la denominada pesca de menor escala.

Luego, se conocerán los conceptos que se engarzan con los principales indicadores de la pesca artesanal a partir del primer censo de la pesca marítima de tipo artesanal en el 2012. Para esto, se tomará como referencia tres departamentos de la línea costera del Perú, por ser los de mayor concentración y notoriedad de embarcaciones y

1 Existen 56,559 pescadores artesanales en el litoral peruano, según el primer Censo de la Pesca Artesanal en el Ámbito Marítimo 2012, realizado por el Instituto Nacional de Estadística e Informática (INEI) por encargo del Ministerio de la Producción (Produce). Por su parte, este indicó que, de acuerdo a un censo elaborado por el INEI, en el país hay 1,822 mujeres que participan en el procesamiento primario de la actividad. 
Figura 1

División de la pesca

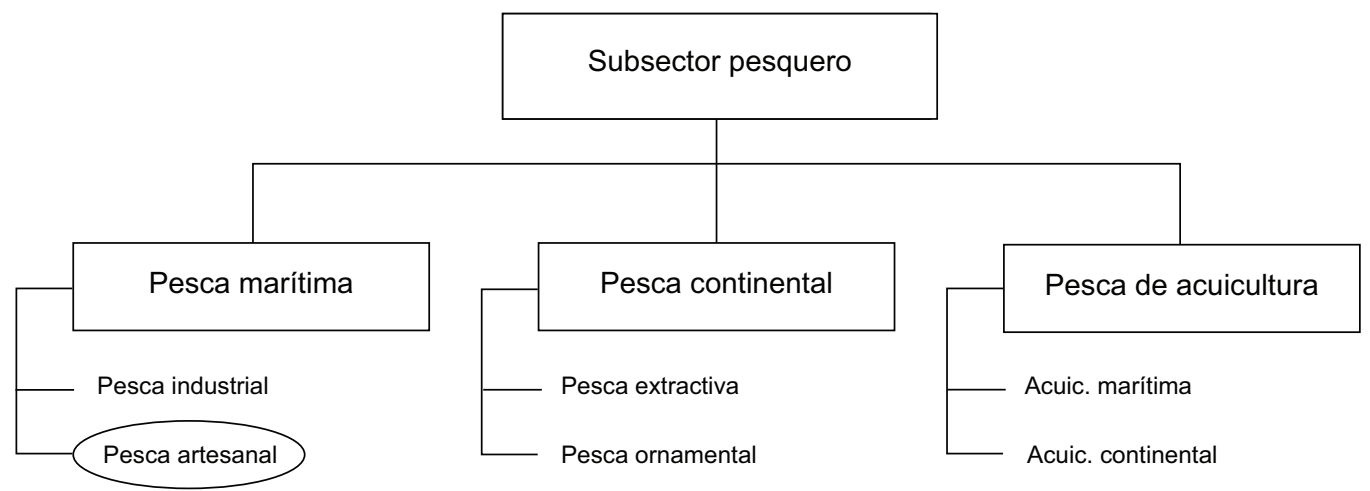

Fuente: INEI, BCRP (2013).

Elaboración propia.

personas dedicadas a la pesca artesanal. El primero de ellos es Piura, departamento que concentra una gran cantidad de embarcaciones y armadores con un $56 \%$ del total en toda la costa peruana. Le sigue Lima y finalmente Ica.

También se ha contemplado el aspecto normativo y legal del subsector, donde se demuestran los vacíos e interrogantes que se presentan al lector sobre la posibilidad de formalizar la pesca artesanal.

En la última parte, se leerán las conclusiones más importantes y sugerencias para que la actividad que hoy actúa bajo un esquema informal pueda en un futuro mediato insertarse en el mundo formal que tanto requiere el subsector. Además, a lo largo del artículo se incluirán conceptos y herramientas de la teoría económica a manera de modelo para describir de forma abstracta y resumida los efectos y comportamiento del subsector.

Finalmente, la metodología empleada para el artículo fue la de observar in situ y describir los hechos tal como son, tratando de responder las interrogantes que se presentan en el subsector y refrendado en las fuentes secundarias de las entidades gubernamentales como el Instituto del Mar del Perú (Imarpe), el Ministerio de la Producción, Dirección General de Capitanías y Guardacostas del Perú (Dicapi), además del 
apoyo recibido de Daniela Supo Calderón, estudiante de Derecho de la Universidad de Lima, quien entrevistó al experto en pesca en el Perú, doctor Richard Inurritegui Bazán², para poder determinar las debilidades y amenazas de la pesca marítima de tipo artesanal a lo largo de la línea costera peruana.

En el presente texto solo abordaremos el estudio de la pesca marítima de tipo artesanal, dejando de lado la pesca marítima industrial, continental y de acuicultura para próximas investigaciones debido a la gran extensión y complejidad del subsector y de sus actores que directa e indirectamente intervienen en el proceso del valor bruto de la producción del país.

\section{LA DESARTICULACIÓN ENTRE EL ESTADO, LA EMPRESA PRIVADA Y LA SOCIEDAD}

En toda la costa peruana, la pesca artesanal o llamada de menor escala es de dominio informal (en muchos casos ilegal); a la que cada día se adhieren más personas sin control alguno, lo que acarreará sin ninguna duda un costo muy alto para la sociedad. Pero no se trata solo de ocupar a más personas, que dentro de la PEA se les denomina como subempleados y con ello disfrazar el desempleo. El peón o tripulante de una embarcación con capacidad de bodega que va desde las cinco toneladas hasta las 26 toneladas percibe ingresos muy bajos y estos pueden variar en función de la captura y el precio según la oferta en el desembarque. Asimismo, la baja productividad del subsector se debe a la escasa dotación en infraestructura para el desembarque y el acopio, el almacenaje, la cadena de frío, los obsoletos equipos en bienes de capital -embarcaciones y motores-, los desaciertos de las políticas de gobierno y la muy lamentable fuerza laboral que cuenta con escasa y baja preparación educativa, todo ello determina los bajos ingresos que se perciben en esta actividad. Esta pérdida de competitividad ha motivado que los agentes y actores de la pesca artesanal pierdan el interés por insertarse en el mercado formal. Las reglas extralegales que se originan conllevan a muchas familias del subsector a no salir del círculo de la pobreza que se evidencia a simple vista por la preca-

2 Experto en asesoría a empresas pesqueras y de recursos naturales en sus actividades extractivas y productivas, licencias, permisos, concesiones, temas corporativos y relaciones institucionales. 
riedad de sus viviendas y del entorno familiar por sus escasos recursos para cubrir la canasta alimentaria y la satisfacción de las necesidades básicas ${ }^{3}$; además de que no se invierte en una mejor calidad educativa, en previsión médica o de un seguro de vida. Simplemente, los ingresos son muy bajos y no permiten contar con capacidad de ahorro y con ello invertir para su crecimiento o realización personal.

La falta de articulación entre el Gobierno, la sociedad y la empresa privada es lo que no ha permitido que el subsector de la pesca marítima de tipo artesanal tenga un mayor dinamismo o crecimiento en la composición del valor bruto de la producción local. Esta desarticulación es la que no ha podido frenar el crecimiento de la informalidad y con ello el efecto visible del desorden, el poder de mercado y las externalidades negativas como la contaminación de residuos, tal como los derrames de aceite, petróleo y combustibles en general en las zonas cercanas al litoral, como en las playas y en los mismos desembarcaderos o muelles artesanales. Esta mala competencia, o falla de mercado, acarrea un estilo muy deplorable por la manipulación desde el momento de la captura, y del intermediario hasta el consumidor final. Todo este proceso se realiza con escaso control sanitario por la carencia de surtidores de agua y por la falta de drenajes que recolecten los desperdicios sólidos de las especies marinas en el momento del eviscerado o del desconchado de los moluscos o crustáceos. Asimismo, una característica recurrente en cada punto de acopio o compra directa de la captura en el mismo muelle o desembarcaderos de pesca artesanal (DPA) es la zona tugurizada, con excesivo tránsito de camiones refrigerados (con cámaras para la transportación del pescado con hielo), además de ser una zona pestilente e insalubre ${ }^{4}$. Los DPA o los terminales pesqueros dentro de Lima

3 El Instituto Nacional de Estadística e Informática (INEI) describe como necesidades básicas insatisfechas (NBI) las siguientes: carencia de servicios básicos en el hogar o asentamientos humanos donde en cada vivienda no hay agua potable, alcantarillado, desagüe, material noble en la construcción de cada habitación, salud, educación ni medicina preventiva. La mayoría de los pobladores que se dedican a la pesca de tipo artesanal viven en hogares que tienen dos a tres necesidades básicas insatisfechas y con ello se ubican en el nivel pobre de la población local.

4 Es común ver estas externalidades negativas (que no son parte de la medición del producto bruto interno), las cuales afectan a toda una comunidad o poblado sin que existan soluciones por parte de una institución del Estado que sea capaz de regular y formalizar la actividad de la pesca de tipo artesanal. Como 
metropolitana, como el de Pucusana (sur) o el de Ancón (norte), son una muestra visible de lo descrito líneas arriba. Es inadmisible que el Gobierno central le reste importancia a esta lamentable situación sin medir las consecuencias adversas por las condiciones de bajo estándar en que se desarrolla la mal llamada pesca artesanal, cuando en realidad es una pesca informal sin control alguno, y que distorsiona toda posibilidad de mejora para el consumidor final y de las personas que se dedican diariamente a esta actividad para sobrevivir.

\section{LA PARADOJA DE LA AGONÍA DE LA PESCA MARÍTIMA DEL TIPO ARTESANAL EN EL PERÚ}

La amenaza contra el crecimiento sostenido y el no poder alcanzar el pleno empleo (PBI real igual al PBI potencial) se deben en parte a la falta de competitividad. Para alcanzar dicha meta se deben priorizar los mecanismos institucionales con el fin de que las actividades extractivas de carácter informal puedan ser formalizadas. Es un tema sumamente sensible y que requiere de una política de Estado con actores vinculantes en todo el proceso (descripción de los hechos, conocimientos teóricos, diseño de políticas y control o medición de los resultados).

Actualmente, el Perú está pasando por un momento complicado con el aumento desmedido de la actividad minera informal para extraer el oro con técnicas de explotación muy cuestionadas que destruyen y alteran el entorno natural, depredando y contaminando de manera irreversible la cadena de vida constituida por las grandes extensiones de hectáreas de bosques de la Amazonía peruana, además de la conta-

muestra, el lector podrá constatar el aspecto deplorable de los ambientes donde se realiza la transacción de la captura (pescado y mariscos) del bote a la playa, muelle o desembarcadero para la venta directa al público. Además de las actividades complementarias como la venta de hielo en escama para el pescado fresco, de comida ambulatoria, de combustibles para los motores de las embarcaciones sin prevención alguna, de aparejos menores para las embarcaciones y peones de lanchas o botes que pululan en función de esta actividad de la pesca marítima artesanal, que en lugar de mejorar la calidad de vida del pescador y de sus familias los empobrece en beneficio de unos pocos oportunistas; bajo la fachada de pertenecer a la pesca artesanal, se esconden inversionistas de mediana talla (existen varios propietarios de lanchas con motor que tienen entre tres hasta cuatro unidades) para eludir el peso de la responsabilidad y el pago de los impuestos como agente formal. 
minación de los ríos que sirven de vertederos de los químicos e insumos son usados para separar las impurezas del metal (concentrados en su mayoría en Madre de Dios, Junín, Pasco, Huancavelica y Arequipa). El gobierno del presidente Ollanta Humala Tasso ha dado el primer paso para erradicar este flagelo que daña la naturaleza y a la sociedad, pero solo una cifra menor al $1 \%$ pudo formalizarse ${ }^{5}$ a pesar de que se otorgaron las facilidades para que con el tiempo los mineros mal llamados "artesanales" (ilegales) pudieran concretar sus trámites y con ello seguir la explotación minera de manera racional y formal. Sin embargo, lamentablemente prefirieron optar por el camino de la destrucción, y siguen restando la competitividad al país para poder alcanzar el pleno empleo con una economía más sólida y con mejores ingresos per cápita.

Si el Estado no es efectivo en el diseño de las políticas y estrategias para formalizar las actividades extractivas, es muy probable que en unos años más, se vea a lo largo de nuestro litoral y a pocas millas de la costa la desaparición de especies ya no tan comunes para el consumo humano directo como el tramboyo, la chita, el lenguado, la corvina, la cabrilla, la cabinza, el cherlo, la pintadilla, la doncella, la reineta, el ojo de uva y el mero. Actualmente, adquirir una de estas en el mercado es complicado por su carestía y sus altos precios que pronto se convertirán en un bien de lujo y que solo una minoría con alto poder adquisitivo podrá disfrutar. Además, resulta complicado obtener otras especies de moluscos, como el chanque (abalón), caracoles, almejas, conchas de abanico (en su estado natural) y choros.

Es una constante amenaza para las próximas generaciones que el subsector no pueda ser sustentable en el tiempo y con ello se perdería un recurso natural valioso por su alto contenido proteico, nutricional y

5 Según el diario El Comercio (Lima, 27 de abril de 2014, p. A6), menos del $1 \%$ de los mineros se formalizaron desde el 2012. De los 200,000 mineros ilegales que operan en el Perú, menos del 1 \% lograron formalizarse por completo el pasado 19 de abril del 2014, último día de un proceso que se inició hace dos años. La Sociedad Peruana de Derecho Ambiental (SPDA) indica que existen cinco obstáculos que explican el porqué del fracaso del proceso para la formalización de la minería ilegal e informal: 1. Falta de capacitación y de recursos en el Gobierno regional. 2. Eliminación de plazos intermedios ante la presión de los mineros. 3. Los cuellos de botella que generaban algunos requisitos. 4. Ausencia de mecanismos diferentes para la minería aluvial (selva) y para la minería de socavón (resto del país) y 5 . Falta de compromiso de los mineros para obtener la formalización. 
agradable para la alimentación de millones de peruanos que necesitan de estos alimentos para su dieta diaria.

A pesar de la gran extensión de territorio costero que tiene el Perú, hay lugares visiblemente concentrados en pequeñas caletas, distritos que sobreviven gracias a la pesca artesanal (informal). Estos poblados se concentran en mayor número entre los departamentos de Áncash hasta Piura (norte del país) y por el sur Ica y Moquegua. El Perú posee unos de los mares con mayores recursos en su estado natural y de gran riqueza en nutrientes en toda la cadena alimenticia marina, pero se corre el riesgo de depredar y contaminar las zonas costeras (caletas, puertos) y con ello se llegaría a la desaparición de muchas especies marinas que pululan en grandes cardúmenes del tipo pelágicas y que se desplazan en los estratos superficiales del ámbito marino.

En las 200 millas del mar peruano existe una gran biomasa que con responsabilidad ambiental se podría convertir en riquezas con más valor agregado y con ello aumentar la participación del subsector en el PBI peruano, mejorando los niveles de ingresos de la población local que directa o indirectamente participan en las múltiples actividades alrededor de la pesca marítima.

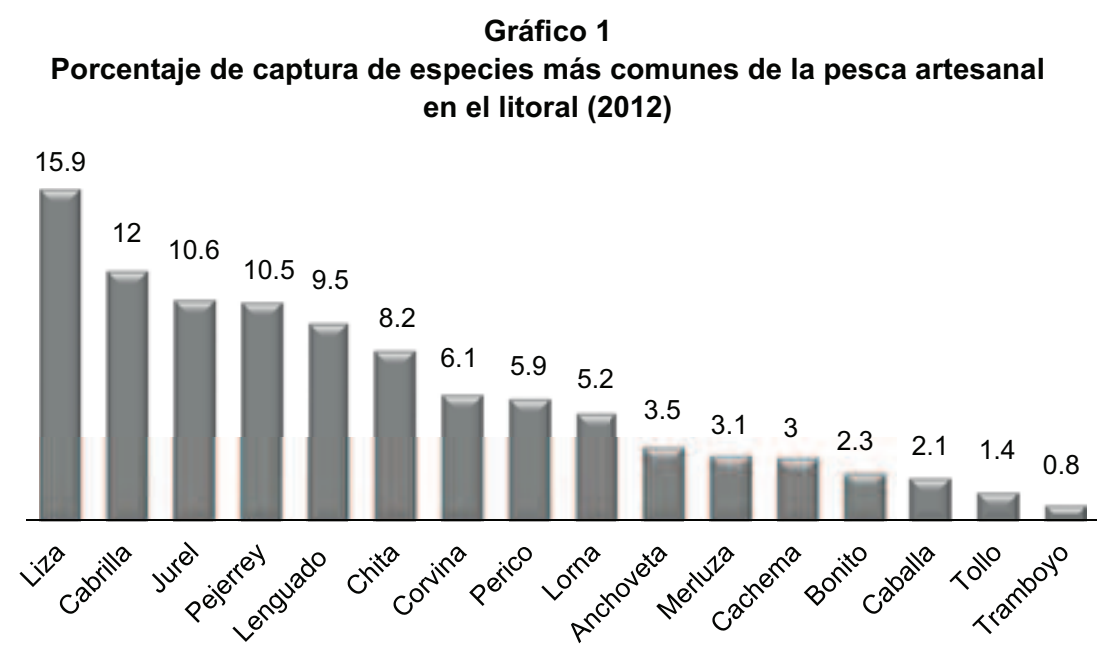

Fuente: Ministerio de la Producción (2012).

Elaboración propia. 
Es importante resaltar que gran parte de la pesca para el consumo humano directo (sin incluir la pota) puede proceder de la variedad demersales $^{6}$, presentados como: curado $^{7}$, fresco o enlatado.

En cada tipo de captura se requerirá una técnica con aparejos adecuados para cada embarcación.

\section{Gráfico 2}

Porcentaje de aparejos más utilizados en la pesca de tipo artesanal (2012)

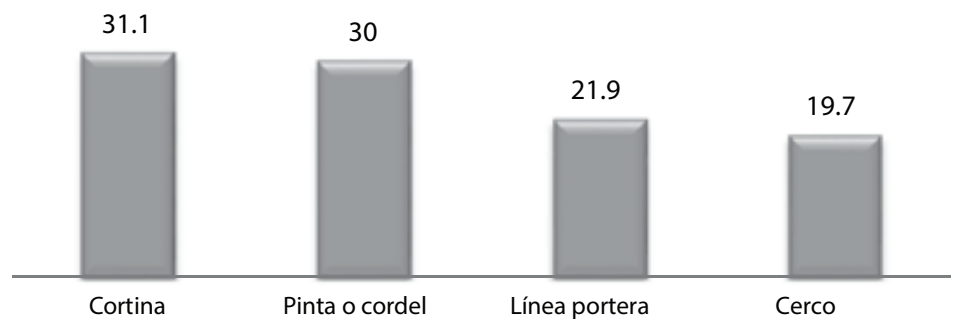

Fuente: Ministerio de la Producción (2012).

Elaboración propia.

Se denomina cortina al tipo de diseño de redes que se utiliza en las embarcaciones que requieren entre cuatro y cinco tripulantes (peones), los cuales capturan especies como bonito, cojinova, pintadilla y cabinza. En cambio, la de tipo cerco se utiliza para la pesca de anchoveta, caballa y jurel.

6 Demersales: recursos hidrobiológicos que viven y se desplazan cerca del fondo marino para la realización de algunas de sus funciones vitales.

Pelágicas: recursos hidrobiológicos que viven y se desplazan en los estratos superficiales y del ámbito marino en grandes cardúmenes.

7 Curado: proceso de conservación de un recurso hidrobiológico mediante el uso de la sal y humo entre los cuales se incluye productos como el salpreso, seco salado, ahumado y el salazón industrial.

Enlatado: producto elaborado mediante un proceso de conservación del recurso hidrobiológico a través de envasado en recipientes metálicos sometidos a altas temperaturas y a presión con fines de esterilización. 
Fotografía 1

Embarcación para pesca artesanal estándar

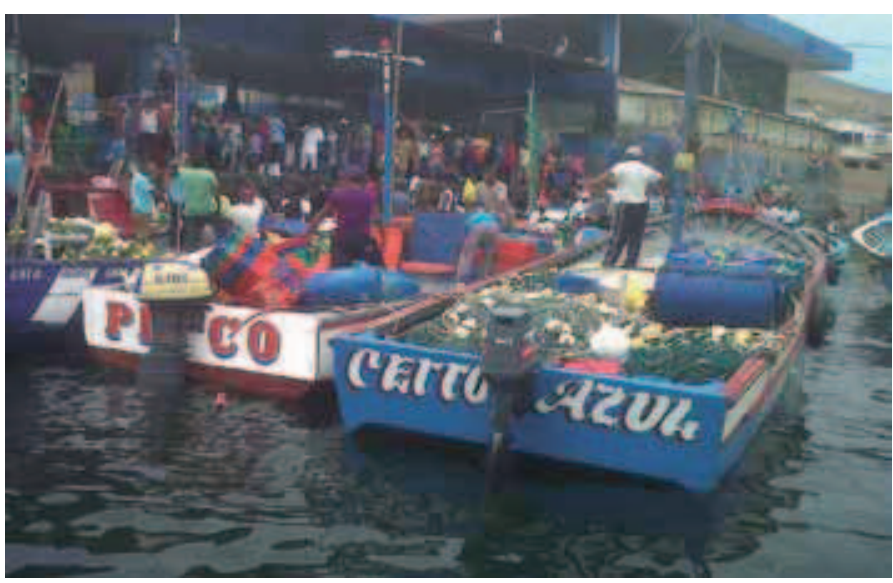

Terminal pesquero de Pucusana.

Fotografía 2

Embarcación con espacio hasta para 26 toneladas

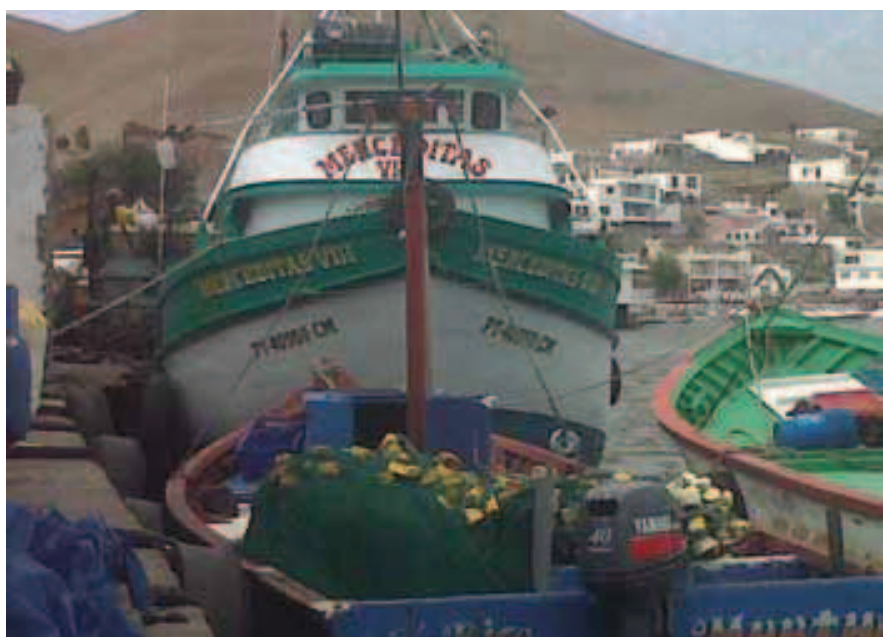

Merceditas.

En la fotografía 1 se aprecian las diferencias de medida en cada embarcación que se dedica a la pesca marítima artesanal. La embarcación Merceditas (fotografía 2) almacena en su bodega insulada cerca de veintiséis toneladas de captura, mientras que el estándar de almacenaje de las embarcaciones del tipo artesanal es de cuatro toneladas mediante la técnica cortinera. 
Mientras en la pesca marítima artesanal se siga con técnicas rudimentarias, con bajo rendimiento de captura, estrecho margen de beneficios por bodega, en vez de buscar una salida formal se continuará en el círculo vicioso haciéndose llamar pesca artesanal cuando en realidad se comporta como una pesca de consumo humano directo ilegal de mediana escala. Si hoy se realizara un segundo censo sobre la pesca marítima artesanal, con toda seguridad se vería que en tan solo dos años ha aumentado la flota de embarcaciones de mayor calado con una tipología que ya no se ajusta a la artesanal. Hoy se observa en cada muelle o caleta embarcaciones fondeadas de proporciones mayores con capacidad de bodegas que oscilan entre las $26 \mathrm{~m}^{3}$ y las $32 \mathrm{~m}^{3}$. Dichas embarcaciones tienen una autonomía para estar en el mar por 6 a 7 días, operadas por 7 tripulantes y navegando entre las 600 y 800 millas (Chimbote a Ilo) paralelamente a la línea costera en busca de peces más grandes, con la ayuda de aparejos más sofisticados para justificar la inversión realizada y con ello obtener las ganancias esperadas.

¿Por qué no ser una unidad de producción que opere correctamente y compita como una empresa unipersonal o asociada, como una pyme o mype, y contribuya con el Estado como cualquier empresa formal?

El problema se ha ido de las manos y se ha dejado a libre albedrío el aumento del número de embarcaciones mal llamadas artesanales (utilizando el nombre como fachada). Ello ha originado rendimientos marginales decrecientes en cada punto de acopio, de los muelles artesanales o de los desembarcaderos de pesca artesanal DPA. Sus agremiaciones reclaman, como empresas formales, invertir en infraestructura y ganar como tales, pero en el accionar siguen como informales diciendo que pertenecen a la pesca artesanal. De este modo evaden responsabilidades, costos que restan ganancias y se manejan en la extralegalidad en busca de alcanzar el poder del mercado informal con beneficios a costa de externalidades negativas para la sociedad.

¿Podrá seguir sobreviviendo la pesca marítima de tipo artesanal?

Todo parece indicar que el pescador debida y claramente identificado como artesanal no tendrá margen de maniobra ni posibilidades para alcanzar un mejor sustento de vida. La informalidad y la ilegalidad se están gestando y creciendo en mayor proporción, pero con embarcaciones más grandes y requeridas para navegar durante más días y a la vez más alejadas de la costa. Si no se corrige esta falla en el mercado mediante una política de Estado, con institucionalización y articula- 
ción de los agentes privados y de la sociedad, lamentaremos pronto un mayor desorden producto de la complacencia y desidia de los gobiernos que declinaron su accionar por el costo político.

\section{Gráfico 3}

Pescadores artesanales marítimos por regiones

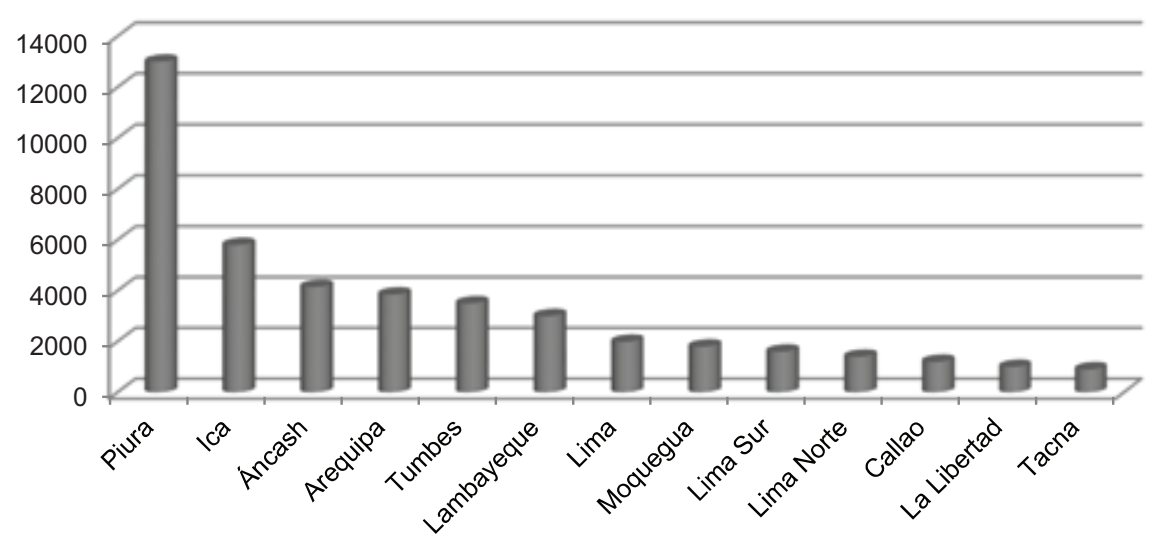

Fuente: Ministerio de la Producción (2012).

Elaboración propia.

\section{Gráfico 4}

Número de armadores artesanales (también pescadores artesanales) al 2012

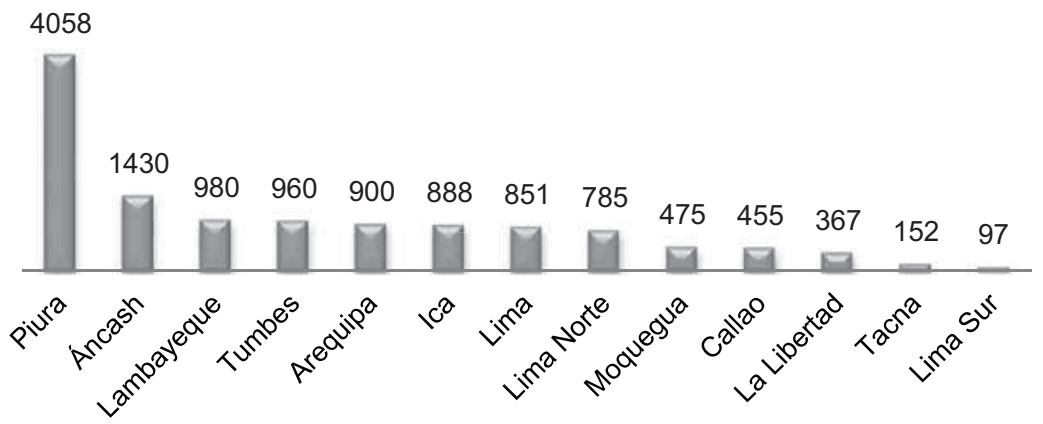

Fuente: Ministerio de la Producción (2012).

Elaboración propia. 
Tabla 1

Estimación de costos para embarcaciones artesanales (en dólares)

\begin{tabular}{lcr}
\hline \multicolumn{1}{c}{ Tipo de embarcación } & Cerquera de $\mathbf{5} \mathbf{~}$ \\
\hline Especie & jurel & \\
kg/día de pesca & 1,000 & \\
Días de pesca / año & 145 promedio* & \\
\hline Costos & Dólares & $\%$ \\
\hline Costos variables & $22,705.85$ & 68 \\
$\quad$ Tripulación & $18,694.18$ & 56 \\
$\quad$ Lubricante y grasa & $2,484.00$ & 7 \\
$\quad$ Víveres & 782.46 & 2 \\
Costos fijos & $1,048.55$ & 2 \\
$\quad$ Mantenimiento & $4,232.00$ & 32 \\
$\quad$ Depreciación & $6,231.39$ & 13 \\
$\quad$ Gastos generales & 21.60 & 19 \\
\hline Total de costos & $3,319.39$ & 0 \\
Total de ingresos & $44,629.20$ & 100 \\
Utilidad & $11,438.81$ & \\
Costo por kg & 0.23 & \\
\hline
\end{tabular}

Fuente: Kleeberg \& Rojas (2012).

Elaboración propia.

Señalar los días de pesca es algo relativo, pues dependerá de múltiples factores: clima, permisos, vedas, aparejos adecuados, mantenimiento del bote, tipo de motores y cambios en la reasignación en el tipo de captura según especie o de embarcación para la pesca.

El tema de costo en esta actividad no es exacto, por la misma naturaleza que se presenta en la pesca, ya que no se puede determinar cómo será este en una ecuación matemática. Hoy el pescado puede estar cerca o muy lejos de la costa y ello nos conduce a variar todas las estimaciones previstas. 


\section{PARTICIPACIÓN DEL SECTOR PESCA EN EL PBI REAL}

El valor de la producción del sector pesca en millones de nuevos soles con respecto al PBI real (precios de 1994) fue ligeramente oscilante y constante entre los años 2001 y 2013, fluctuando en una banda donde el mínimo registrado se dio el año 2003 con un valor de producción equivalente a los S/. 596 millones y un máximo de S/. 996 millones durante el 2011. Asimismo, cabe resaltar que la composición del sector pesca está muy diversificada ${ }^{8}$ y para los fines de este trabajo solo se ha considerado el subsector pesca marítima artesanal. Ello se traduciría en un importe mucho menor estimado (no mayor al $20 \%$ del total de las cifras adjuntas en la tabla). En términos de porcentajes la contribución o participación del sector pesca en el PBI real no supera el 0,6\% del PBI total ${ }^{9}$ (menor al $1 \%$ ), pero si se hablara de la pesca solo artesanal es un porcentaje casi nulo en términos comparativos. El lector se preguntará el porqué de un porcentaje tan reducido en la composición y estructura del PBI si el país cuenta con una línea costera que se extiende un poco más de 3,000 kilómetros, ocupando una zona marítima hacia el oeste con una línea imaginaria a 200 millas de distancia (370.4 kilómetros del punto más cercano de la costa) con una totalidad de extensión cercana a 1,140,600 kilómetros cuadrados, donde presenta una importante biomasa de zooplancton y fitoplancton, con más de 600 especies de peces y una inmensa variedad de mamíferos marinos, moluscos, crustáceos y toda una diversidad de fauna marina que hace del mar peruano uno de los más ricos del mundo.

8 Para el sector pesquero se considera la pesca marítima que se destina al congelado, enlatado, curado, fresco, de anchoveta y otras especies (jurel, sardina y caballa) y de la pesca continental (fresco y curado).

Se realiza un seguimiento mensual de la producción en cerca de 230 establecimientos. Para el rubro de harina y aceite se tiene 104 establecimientos que cubren el $90 \%$ de la pesca desembarcada, en el rubro enlatado se sigue a una muestra de 65 establecimientos que se hallan operativos, cubriendo un $70 \%$ de la información. Para las especies en estado fresco, la información se recoge de los principales puertos de desembarque: Piura, Ilo, Lambayeque, que son consecuentes con los datos del volumen ingresado en mercados mayoristas de pescados y mariscos.

9 "Si tenemos una ampliación de esos recursos, la producción pesquera ya no va a caer como ocurrió en el 2013, se va a recuperar. Eso implicaría que la participación del sector pesca en el PBI subiría entre 0,5\% y 1\%” (BCRP, 2014). 
Este mar presenta una gran promesa para la actividad industrial, pero esta debe ser responsable, precisamente lo que no se hizo hace años.

\section{Gráfico 5}

Porcentaje de participación de la pesca en el PBI

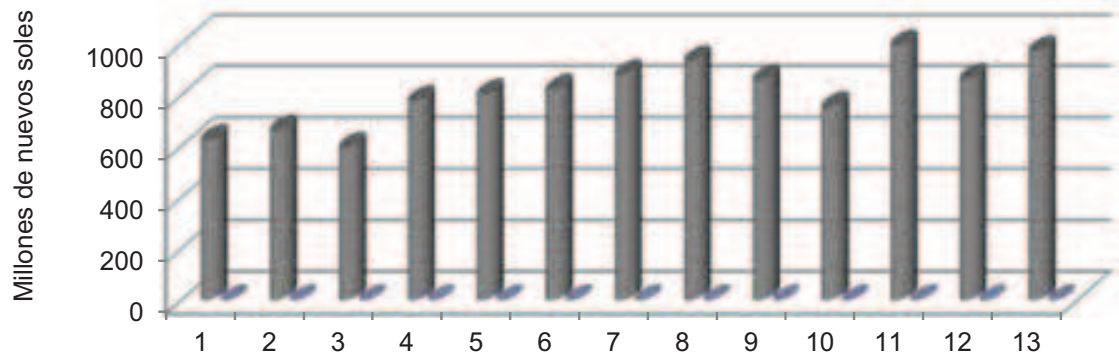

Fuente: INEI, BCRP (2013).

Elaboracion propia.

Aunque parezca inverosímil, en la década de 1950 hasta los inicios de los años sesenta, durante los gobiernos de Manuel Odría (19481950 y $1950-1956)^{10}$ y del segundo periodo de Manuel Prado Ugarteche (1956-1962) no se tenía aún conocimiento del potencial de los recursos hidrobiológicos marinos, que luego serían una fracción de la riqueza (transformado y medido en el PBI real) como parte de la dieta cotidiana de la población del Perú; mucho menos de su transformación e industrialización en gran escala. Solo existía un mercado muy pequeño compuesto por pescadores de la zona que ofrecían de manera muy artesanal la captura del día.

Eran épocas que en cada localidad costera abundaban especies muy cercanas a las costas por la escasa presencia del hombre y de las industrias que contaminaban las playas y los mares. Era común encontrar platos a base de pulpo, cangrejo, cojinova, bonito, tramboyo, pejesapo, macha, almeja, concha de abanico, caracol, choro, pejerrey, ojo de uva, cabrilla, chita, lenguado y corvina.

10 De 1948 a 1950 como miembro de la junta militar y de 1950 a 1956 como presidente constitucional. 
Durante las décadas de 1960 y 1970 presenciamos el boom de la pesca de la anchoveta para su transformación industrial en harina de pescado para el consumo humano indirecto. Al respecto, Fernando Kleeberg y Mario Rojas señalan: "El Perú llegó a ser el primer productor y exportador de harina de pescado en el mundo en 1970. En ese mismo año se exportó 1.873 .000 toneladas que a la cotización de ese entonces (102 dólares/t) significó un ingreso de 303 millones de dólares, casi el $30 \%$ del total de las exportaciones peruanas" (2013, p. 13).

De esta manera, el mundo desarrollado había encontrado en países como el Perú esta nutritiva materia prima para sus industrias de tipo agropecuarias, que compraban a precios bajos.

Nuestro país se convirtió en un gran proveedor de harina de pescado y con ello, condenó casi al exterminio a la anchoveta por la práctica de una captura irresponsable (tipo cerco) y que además contribuyó a dos efectos perversos para la economía. El primero de ellos fue la migración rural a las ciudades costeras del Perú para dedicarse a la actividad de la pesca marítima y ello produjo un descuido del campo, por lo que apareció el desempleo estructural en ciudades de los departamentos de Piura, Lambayeque, Áncash, Callao, Lima, Ica y parte de Moquegua. El otro efecto negativo fue la secuela de la mala práctica industrial que dejó contaminadas muchas bahías y caletas con desechos (borra), desperdicios de las harineras de pescado, combustibles y aguas servidas. Si a todo ello le sumamos el desorden que trajeron las actividades que prestaban servicios de equipamiento, provisiones, aparejos, víveres entre otras de índole ilegal, muchas zonas, poblados, distritos de veraneo y playas con potencial turístico se convirtieron en verdaderos centros de mal vivir, lo que generó el empobrecimiento que aún se observa a lo largo de la línea costera del Perú, como los casos de Chimbote, en Áncash, y de Pisco, en Ica.

Durante los últimos gobiernos, que pasaron por el péndulo de sistemas económicos y estilos entre militares y democráticos, así como de tendencias intervencionistas o liberales, nunca se supo corregir este fallo de mercado (crecimiento informal de la pesca artesanal) y no se prestó la debida atención para corregir los excesos de las cantidades ofertadas como de las demandadas de la captura destinada al consumo humano directo e indirecto, y con ello el Perú perdió posiciones estratégicas en la competitividad del sector. Si además le agregamos la ausencia de una política de Estado con el fin de elevar la productividad de los actores y agentes dedicados a la pesca marítima artesanal 
para articular de manera sistemática la cadena de valor-trabajo hasta alcanzar al consumidor final, diremos con justa razón que comer pescado fresco, congelado o enlatado se ha convertido en un lujo. Durante casi sesenta años se ha dejado a la deriva la pesca artesanal y con ello se tuvo como respuesta la informalidad del sector. Se crearon externalidades negativas como la contaminación, el poder de mercado y las colusiones (mafias) típicas en organizaciones sin regulación por parte del Estado, que a la fecha acarrea un costo social muy grande y que no será nada sencillo de corregir.

Para que el lector tenga una idea muy general de lo comentado, el primer censo de la pesca artesanal en el ámbito marítimo se efectuó recién en el 2012. Con los primeros resultados se pudieron elaborar importantes indicadores para recién poder empezar las mediciones, comparaciones, relaciones y diseño de políticas acertivas dirigidas a resolver los problemas del sector. Una gran revelación en los resultados del primer censo fue la de conocer que había 56,000 personas y 16,600 embarcaciones, a lo largo de la costa del país, dedicadas a la pesca marítima artesanal (en su mayoría informales), pero se cree que eran más los actores vinculados a dicha actividad, que no han sido debidamente identificados o detectados en el momento del censo.

Gráfico 6

PBI real del Perú en millones de nuevos soles

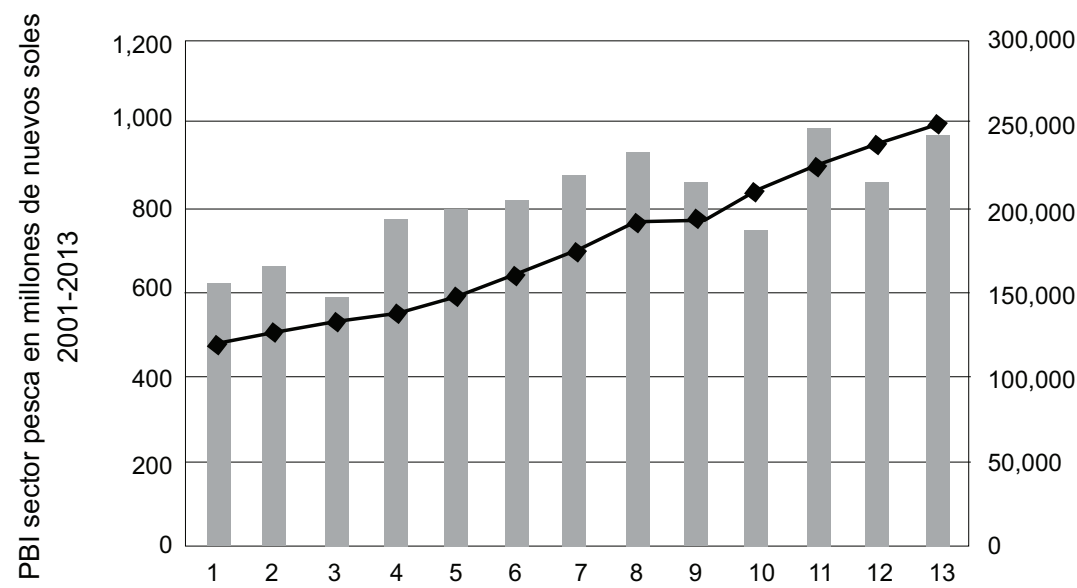

Fuente: INEI, BCRP (2013).

Elaboración propia. 
El promedio del tiempo de uso de las embarcaciones para la actividad artesanal llamadas boniteras, chalanas y botes a remos, así como de motor dentro y fuera de borda, es de cuarenta años, totalmente depreciadas y obsoletas, con una capacidad de bodega que oscila entre los $5 \mathrm{~m}^{3}$ y $15 \mathrm{~m}^{3}$. Sus bodegas no están equipadas y se adquiere hielo tipo escama para almacenar la captura y cubrirla además con sal gruesa; puede permanecer así hasta 48 horas antes de ser desembarcada en el puerto. Además, los pescadores operan con aparejos muy artesanales, exponiendo sus vidas por la precariedad de las embarcaciones sin que un seguro o fondo previsional los ampare en caso de una desgracia o la pérdida parcial o total de sus implementos de trabajo.

Quizá ello explique por qué este sector no cuente con mayor porcentaje en la participacion del PBI real del país.

La pesca marítima artesanal requiere una urgente atención para su transformación a través de políticas bien estructuradas que no alteren el crecimiento sostenido del PBI real, con el fin de que sea el eslabón del normal proceso productivo otorgando un mayor valor al producto y evitando la contaminación del medioambiente; así, dichas políticas generarán más puestos de trabajo formales y la riqueza del país se distribuirá de manera más equitativa.

Los ingresos promedio que percibe cada persona dedicada a la pesca marítima de tipo artesanal, ya sea como peón de lancha, armador o propietario de su propia embarcación son bastante limitados. Además, la pesca para el consumo humano directo es una actividad cíclica, que depende de factores climatológicos, temperaturas de las aguas y políticas de veda para cada especie, que coloca al pescador en una situación muy vulnerable en su propósito de obtener su sustento y el de su familia; para Hernando de Soto:

La existencia de una creciente extralegalidad, donde la población de la mayoría de las ciudades del Tercer Mundo se han cuadruplicado o más en las últimas cuatro décadas. Para el año 2015 más de 50 ciudades en los países en vías de desarrollo tendrán cinco o más millones de personas, gran parte de ellas viviendo y trabajando fuera de la ley. Asentamientos y negocios extralegales han adquirido, desarrollado y construido vecindarios enteros en oposición directa a las normas estatales (2000, pp. 115-116). 
Figura 2

Estructura de la población según condición de actividad

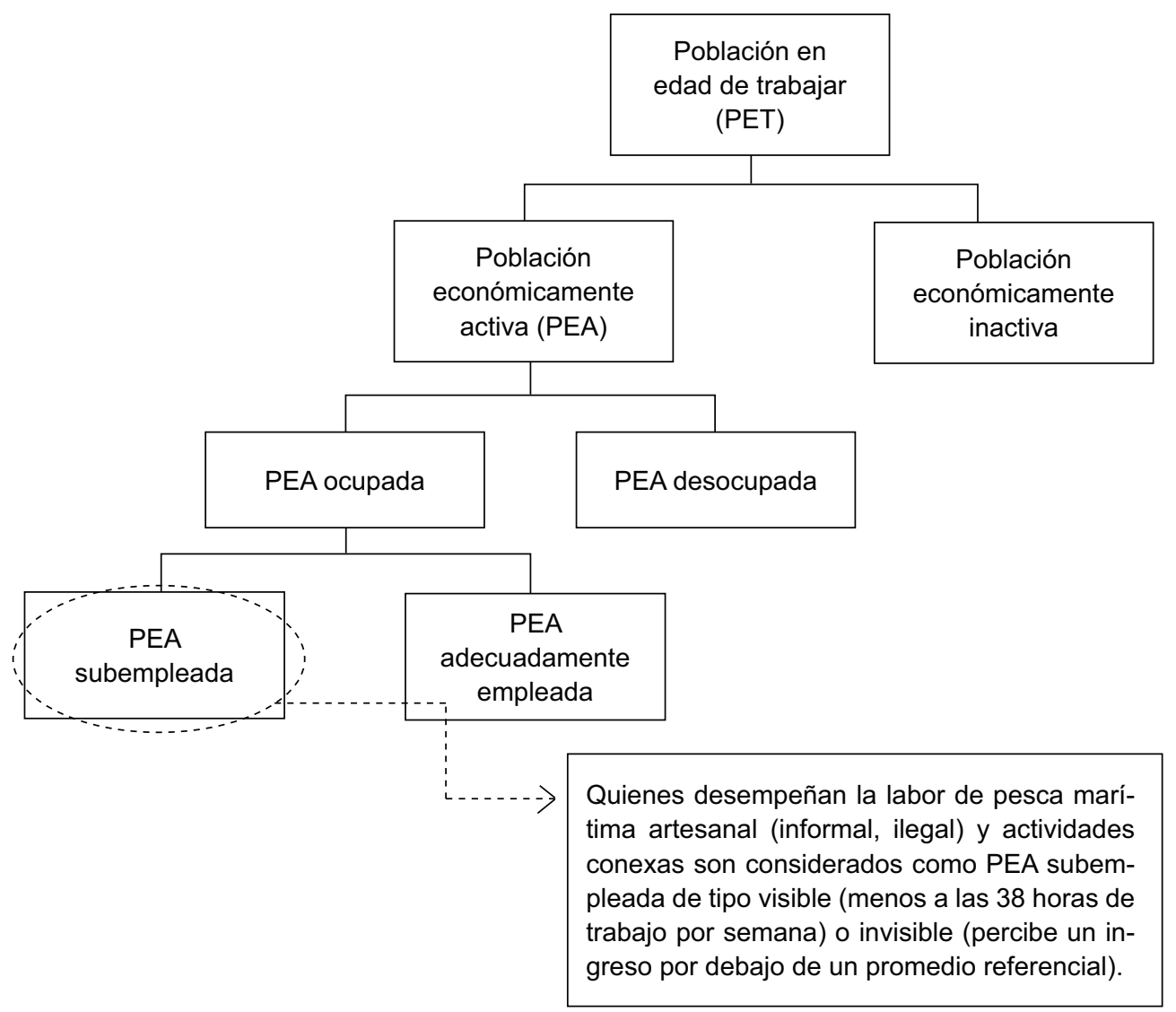

Fuente: INEI (2013).

Elaboración propia.

Los dirigentes y agremiados de la pesca marítima artesanal del Callao comentan que no existe dinero para el mantenimiento de los botes de pesca, y las voces de protesta de los pescadores artesanales no cesan de hacerse escuchar, como se puede ver en el pronunciamiento de la Asociación Nacional de Empresas Pesqueras Artesanales del Perú (Anepap): 
Hoy por la noche, Anepap decidió emprender una paralización de embarcaciones, si el Gobierno aprista no soluciona la problemática de la pesca artesanal. El 28 de marzo, se le solicitó formalmente una reunión al nuevo ministro de la Producción José Nicanor Gonzales para conocer la política pesquera artesanal que desarrollara su Despacho, e informe sobre los Proyectos de desembarcaderos pesqueros Bahía Blanca en Ventanilla y Grano de Oro en Pucusana, sin respuesta a la fecha, informó el dirigente de Anepap, Alejandro Ortiz Saldarriaga (2010).

\section{Además, la Anepap considera que:}

La miseria, inseguridad e informalidad para subsistir son tan evidentes desde muchos años atrás en la pesca artesanal del Callao, que cuenta con una flota de botes y chalanas muy antigua y obsoleta, pero el Gobierno Regional aún no se da cuenta de eso. Hoy ya no solo preocupa esa grave situación socioeconómica al sector artesanal, sino también el estar obligado a coexistir con el peligro para sus botes y chalas, y además, para la vida de sus tripulantes, por la modernización y expansión portuaria que empezó el pasado Gobierno nacional del presidente Alan García, y que irresponsablemente no contempló plan de contingencia alguno para con la pesca artesanal, cuando se concesionaron los Muelles Sur, Norte y el de minerales (2010).

\section{Gráfico 6 \\ Número de naves pesqueras artesanales que operan con y sin permisos para pescar}

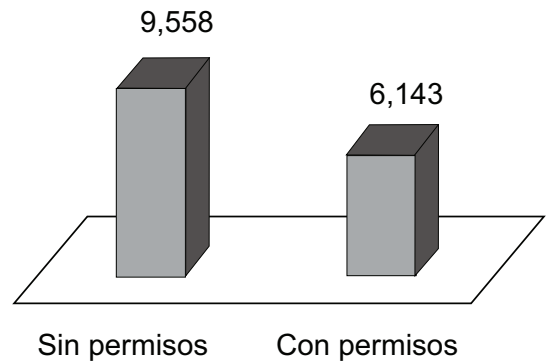

Fuente: Ministerio de la Producción (2013).

Elaboración propia. 


\section{CONDUCTA EN LA PESCA MARÍTIMA ARTESANAL}

Se define la pesca marítima artesanal como una actividad pesquera que utiliza las técnicas tradicionales con escaso desarrollo tecnológico. En ella se observan embarcaciones de menor calado a lo largo del litoral y que navegan a no más de 12 millas de distancia desde la costa hacia el mar territorial. Esta pesca se mantiene en regiones poco desarrolladas donde la producción es escasa y se emplea para el autoconsumo. El excedente se destina para la venta en un mercado o terminal pesquero. Para esta actividad se utilizan botes a remo o a motor, o las chalanas y boniteras cuya capacidad de bodega no excede los $10 \mathrm{~m}^{3}$; se capturan especies pelágicas y demersales, además de mariscos, moluscos y crustáceos.

Sin embargo, uno de los problemas radica en que muchos de los pescadores artesanales actúan dentro de la informalidad, donde campea la ilegalidad sin control alguno. Así, por ejemplo, se ha acuñado el término de pesca de menor de escala y se permiten embarcaciones cuya capacidad de bodega no exceda las $32 \mathrm{~m}^{3}$, capaces de navegar 600 millas o más de manera paralela a la línea costera peruana. Estas embarcaciones utilizan aparejos o equipos más sofisticados con cinco a siete tripulantes (un capataz y seis peones).

Por otro lado, hay casos en que una misma persona posee más de una embarcación, además de camiones para el acopio, y no tributa, aduciendo que pertenece a la pesca artesanal.

Se supone que la pesca marítima artesanal asegura la sostenibilidad de los ecosistemas acuáticos, además de ser una actividad extensiva, a pequeña escala, ejercida directamente por los pescadores, con artes de pesca en su mayoría selectivos. A su dimensión económica, se agrega su dimensión social, pues sostiene el empleo y la calidad de vida de cientos de miles de integrantes de las comunidades costeras.

Los elementos fundamentales que definen la pesca artesanal se relacionan con la racionalidad en la explotación de los recursos pesqueros y la accesibilidad del mundo financiero formal no solo para el capital de trabajo, sino para equipar y mejorar sus técnicas de captura y conservación. Asimismo, es importante que el comportamiento de los actores vinculados con la actividad de la pesca artesanal o de mediana escala se engarce con las nuevas propuestas de una pesca responsable, aplicadas en muchas partes del mundo, y que actúen de manera más 
racional, conscientes de que la formalidad es la única manera de asegurar la sostenibilidad de los ecosistemas marinos.

Por su parte, la pesca industrial responsable tiene como objetivo obtener un gran número de capturas. Por ello necesita capital para equipar los barcos e investigar nuevos sistemas de pesca; tecnología avanzada para aumentar el volumen de capturas, una infraestructura de desembarque donde se pueda recibir y acopiar la captura y distribuir de modo más competitivo.

Las amarras vinculantes en la triangulación Estado, empresa privada y sociedad deben estar en la agenda de las reformas estructurales para fortalecer la institucionalidad del Estado mediante sus dependencias en estrecha relación con los gremios privados, que reclaman una mejor atención al subsector pesca.

Figura 3

Esquema de flujo de servicio y pago en el entorno de la pesca marítima artesanal

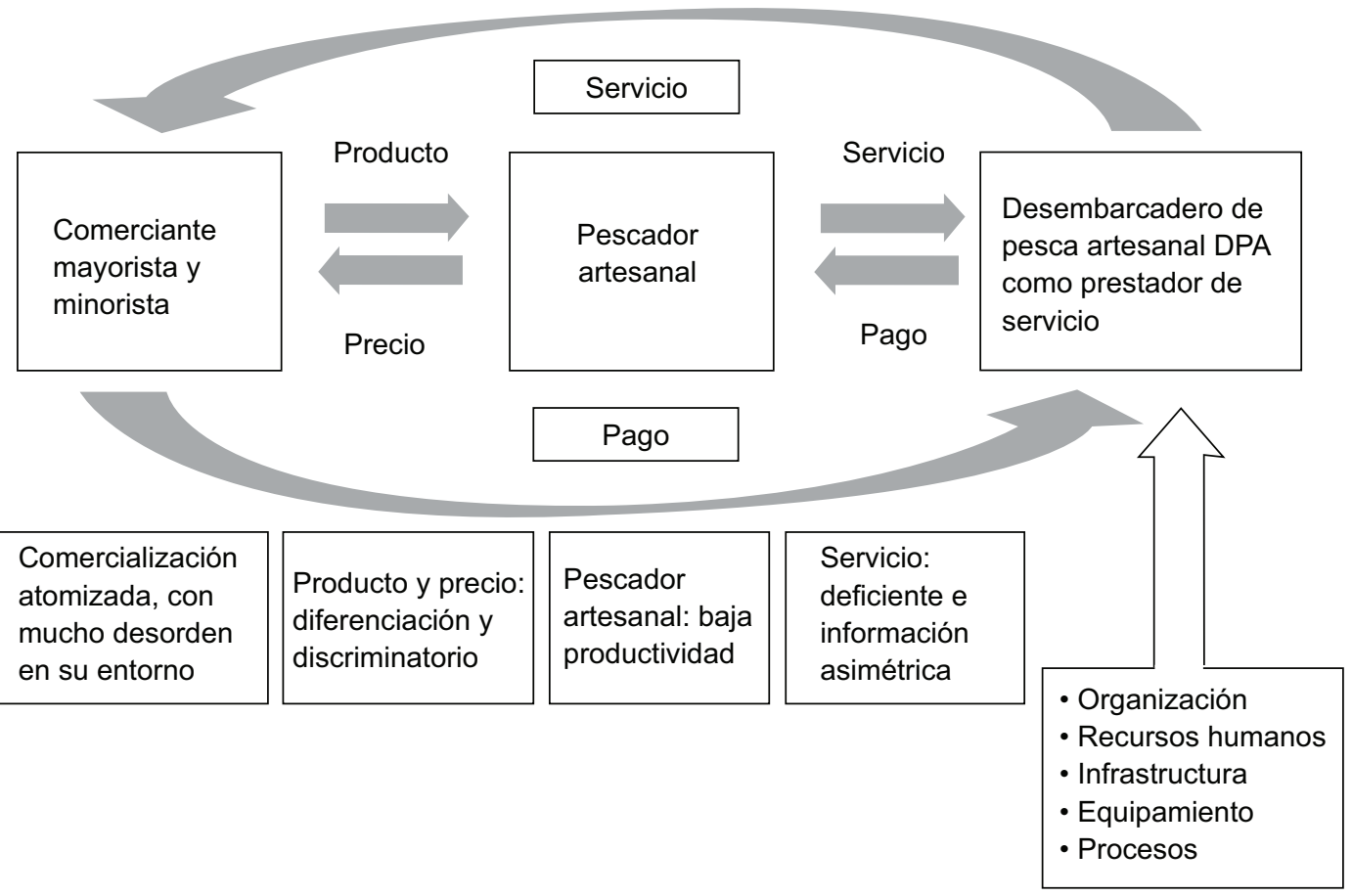

Elaboración propia. 
Si los actores y agentes vinculantes para dinamizar la pesca responsable no duplican sus esfuerzos y las autoridades e instituciones del Gobierno Central no articulan los requerimientos del pescador y armador artesanal, en el futuro se podría ver reducido el volumen de captura de la anchoveta, jurel y caballa para el consumo humano directo.

El Decreto Supremo (D. S.) 005-2012 $2^{11}$, promovido por el Ministerio de la Producción y refrendado por el Congreso de la República del Perú, afectaría la riqueza del subsector, al reducir el volumen de captura en detrimento de la población, la cual requiere mayor cantidad de alimentos.

La reducción de la captura de anchoveta se debió a dos razones ocurridas durante el 2012: la disminución notoria de la biomasa y con ella de la captura de la anchoveta como recurso natural para su transformación, y la incertidumbre generada por el polémico D. S. 005-2012 de Produce, por el que muchos pescadores, de menor escala o artesanales, solo pueden capturar el recurso para el consumo humano directo dentro de las 5 y 10 millas marinas paralelas a la franja costera del Perú.

La franja de la discordia no pasa solo por un tema de demarcación, sino por uno de incentivo económico.

11 El D. S. 005-2012 es un claro ejemplo de lo que ha ocurrido entre los años 2012 y 2013 con la captura de la anchoveta, puesto que las estadísticas muestran que el volumen de captura de la anchoveta ha caído no solo por el calentamiento de la temperatura del agua, sino también por la política de Estado impuesta por el mismo Ministerio de la Producción. 
Figura 4

Flujo de la productividad de la pesca marítima artesanal

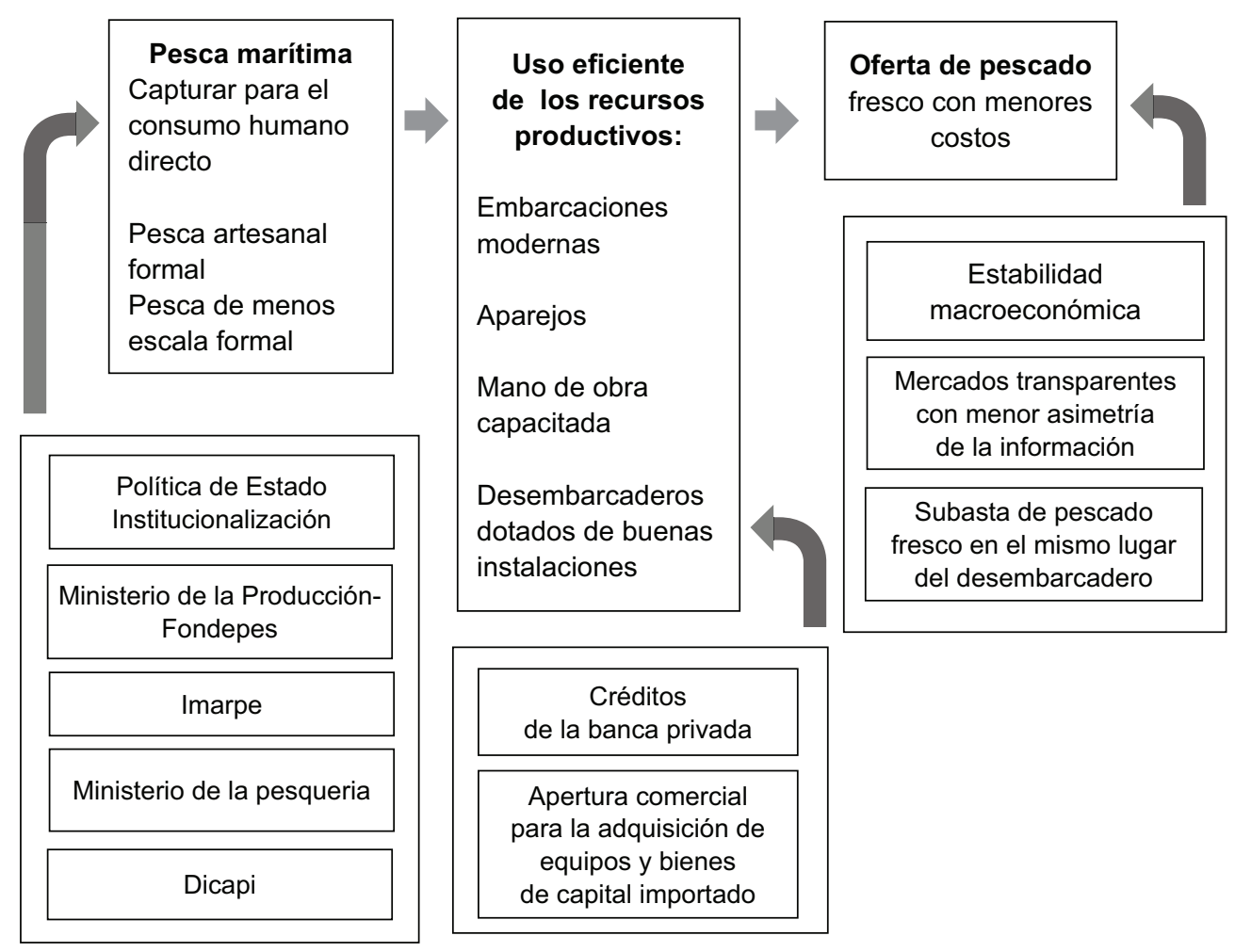

Elaboración propia.

Desde un punto de vista sistémico, es importante observar en el diagrama el posible aumento de la productividad del subsector pesca marítima artesanal, que podría efectivizarse si se articularan el Estado, los agentes privados y la sociedad bajo un entorno estable y de institucionalidad transparente. No es posible seguir aceptando en cada censo que en el factor hombre (pescador y armador artesanales) se concentre un alto porcentaje de trabajadores que apenas cuente con primaria o secundaria completa y un porcentaje casi nulo con estudios técnicos o superiores. 
Como se puede observar en el flujo de la productividad de la pesca marítima artesanal, esta tiene un tortuoso camino por recorrer para que se torne productiva y con ello más competitiva. A priori podríamos justificar los bajos ingresos que perciben los peones, capataces de lanchas y de sus propietarios (también pescadores). Por ello, es recurrente ver como "círculo vicioso" el aumento de más embarcaciones con capacidad de bodega mayores al promedio de las embarciones dedicadas a la pesca artesanal que capturan dentro de las 5 millas marítimas.

Lamentablemente, aún estamos lejos de que se realice un cambio importante por falta de una política de Estado que priorice el sector y reasigne los recursos para alcanzar una producción óptima, que incrementaría su participación en el PBI.

La baja productividad en la pesca de menor escala o artesanal en toda la costa peruana y con ello los bajos ingresos que perciben los pescadores obedece a la nula formalización de la actividad y la inexistencia de acceso a un tipo de seguro para su embarcación o la obtención de crédito para usarlo como capital de trabajo con el fin de rentabilizar su inversión.

$\mathrm{Al}$ tomar como referencia los indicadores elaborados por el INEI según los resultados del primer censo sobre la pesca marítima artesanal, se puede apreciar que casi el $24 \%$ del total de personas involucradas en el sector pertenecen al departamento de Piura, donde además se concentra la mayor cantidad de embarcaciones de mayor calado, con mayor presencia de armadores y astilleros.

Según los resultados del censo de la pesca artesanal (2012), existe un aproximado de 44,161 pescadores artesanales desde Tumbes hasta Tacna y 12,450 armadores que también realizan la pesca artesanal. De ellos, en promedio, menos del $2 \%$ tiene acceso a financiamiento proveniente de las cajas municipales, cooperativas o bancos. Asimismo, la mayoría de los pescadores artesanales informales se concentran en el norte del país, con mayor presencia en los departamentos Lambayeque y Piura.

Obsérvese la estadística del nivel educativo del pescador artesanal y la correlación de los bajos ingresos. Como muestra elegimos el departamento de Piura, donde el $45 \%$ de pescadores artesanales percibe un ingreso de S/. 500 soles por mes, y un $27 \%$ obtiene S/. 1,000 soles mensuales. 
En cuanto a la infraestructura de los llamados desembarcaderos para la pesca artesanal (DPA), los muelles y los terminales pesqueros son casi nulos para el desembarque ordenado del producto. Además, en la mayoría de los casos presentan un aspecto deplorable por estar atiborrados de vendedores informales y ambulatorios de bienes y servicios que sirven de complemento al hombre de pesca, lo que genera una externalidad negativa (contaminación visual). Por otra parte, es notoria la manipulación del pescado desde la embarcación que llega al muelle hasta el punto de venta del minorista, que hace que el producto tenga un precio mayor. En muchos lugares de la costa peruana se observa la escasa cadena de valor desde que se inicia el desembarque del pescado hasta el punto de venta final para el consumidor, donde las condiciones de almacenamiento para mantener fresco el pescado y los mariscos mediante el refrigerado o congelado no son óptimas. La inexistencia de fábricas de hielo en cada DPA o terminal pesquero obligan a la compra de este producto, cuya transportación se realiza en grandes camiones que reducen aún más la zona de maniobra para otros camiones que llevan el pescado a otros puntos de venta o destino final.

Si a todo ello le sumamos la falta de agua potable, de servicios higiénicos, de señalizaciones para el aforo y de las zonas que dictamina defensa civil en caso de desastres naturales, estamos frente a una infraestructura paupérrima que genera escasa productividad, imposibilitando la competitividad de la captura en el mercado. El tipo de mercado que se observa está lejos de lo que sería un modelo competitivo o cercano a la competencia perfecta. Por el contrario, es un mercado bastante informal, donde prevalece el poder de los comerciantes, la información asimétrica de unos pocos acopiadores que distraen el mecanismo racional y eficiente del mercado competitivo frente a lo que podríamos observar en una subasta holandesa de puja de precios descendente o en la inglesa de puja ascendente, que se practica en muchos países pese a tener más restricciones y regulaciones que en el Perú. Hoy la captura de especies marinas para el consumo humano directo se ve amenazada también por las malas prácticas de muchos pescadores artesanales que no cumplen con ciertos protocolos, y por las normas o decretos establecidos por las entidades del Estado como el Instituto del Mar Peruano (Imarpe) y el Ministerio de la Producción (Produce). El ejemplo más reciente es el de la pesca de la anchoveta que se practica dentro de la franja establecida a lo largo del litoral para las embarcaciones de menor escala o del tipo artesanal. En dicha franja se permiten embar- 
caciones de menor escala cuyas medidas en capacidad de bodega no excedan las 32,5 toneladas.

La embarcaciones de pesca artesanal informal tienen bodegas insuladas cuya capacidad de almacenaje oscila entre $5 \mathrm{~m}^{3}$ y $16 \mathrm{~m}^{3}$ (5 a 16 toneladas). Sin embargo, tambien existen embarcaciones, en menor porcentaje, en cuyas bodejas insuladas se puede almacenar entre las $26 \mathrm{~m}^{3}$ y $30 \mathrm{~m}^{3}$ (26 a 30 toneladas) de pescado, a las que se les suele llamar embarciones para la pesca de menor escala (están catalogadas como pesca artesanal) y su accionar es informal. Mediante el Decreto Supremo 005-2012 ${ }^{12}$, el Ministerio de la Producción autoriza las embarcaciones de pesca de menor escala (pesca artesanal) para fomentar la captura de anchoveta destinada solo al consumo humano directo; sin embargo, suelen capturar esta especie para venderla a los fabricantes de harina de pescado, porque estos pagan un precio mayor al del pescado destinado al consumo humano directo (CHD). Sin embargo, hay embarcaciones de mayor calado (llamadas "vikingas") que de manera ilegal capturan la anchoveta para venderla a la industria, mala práctica cuya producción se le conoce como "harina negra").

El tema es muy complejo y poco efectivo, por la ausencia de un buen sistema de control (equipos y supervisores de las entidades competentes del Gobierno central) para hacer respetar la captura de la anchoveta por la pesca de menor escala con fines unicamente de consumo humano directo (98\% para harina y $2 \%$ para el CHD). Lamentablemente, los pescadores informales no tienen miramiento alguno para actuar de manera ilegal y optan por la captura de la anchoveta no para el CHD sino para comercializarla a los industriales de harina de pescado que acopian la anchoveta de los mismos pescadores artasenales (pesca de menor escala) a precios tambien irrisorios, como S/. 250 por tonelada de la captura de anchoveta no apta para el CHD por el tipo de almacenamiento.

12 El Decreto Supremo 005-2012, promulgado en agosto del 2012, fue a juicio de los científicos consultados un primer paso para incentivar el consumo humano de la anchoveta. Esta ley reafirma las primeras 5 millas de la costa para las embarcaciones artesanales; otorga la franja de 5 a 10 millas para la flota de menor escala y desplaza a los buques industriales de las gigantes pesqueras peruanas a partir de las 10 millas. La misma ley obliga a las embarcaciones de menor escala a contar con sistema de control satelital para vigilar sus lances de pesca, prohíbe la instalación de más plantas de harina de pescado y decreta el cierre de estas tras dos infracciones consecutivas. 
Antes de que se promulgue el D. S. 005-2012, los pescadores artesanales de embarcaciones denominadas bolichito ${ }^{13}$ fuera de borda del puerto de Ilo (Moquegua) respaldaron el D. S. 010-2010 y manifestaron su total rechazo a sus pares que de manera ilegal se coludían con el empresario inversionista y acopiador de anchoveta para procesarla en harina de pescado:

Que lanchas semiindustriales "vikingas" infiltradas en nuevas asociaciones de armadores artesanales estén más interesadas en capturar anchoveta dentro de las 5 millas marinas y convertirla en harina de pescado. Evitando que nuestro pueblo coma el recurso anchoveta de ingentes proteínas para nuestros niños yéndose de esta manera en contra de la inclusión social que promueve nuestro gobierno nacional (OANNES, 2011).

En otro capítulo se afirma:

Los pescadores artesanales bolichitos fuera de borda le manifestamos nuestro total rechazo y manera de proceder que vienen teniendo los señores inversionistas agrupados en diferentes asociaciones de armadores y que vienen promoviendo la captura de anchoveta para la harina de pescado dentro de las 5 millas marinas. La manera irresponsable de proceder de ustedes nos afectará enormemente si es que consiguen que les permitan pescar anchoveta para la harina dentro de las 5 millas marinas. Esa es la razón por la que no podemos estar unidos con quienes pretenden pescar anchoveta para la harina de pescado dentro de las 5 millas marinas poniendo en grave riesgo el repoblamiento de la anchoveta y los peces que se alimentan de ella. Señores les pedimos coherencia en sus planteamientos. La presión que desarrollan no es la mejor solución para los problemas de la pesca artesanal (OANNES, 2011).

Esto generó una discusión económica y legal sobre los costos y beneficios que resultarían de aplicar el D. S. 005-2102 y por eso los industriales y pescadores artesanales abogaban por su derogación. En el 2013 la ministra de la Producción, Gladys Triveño, ${ }^{14}$ fue interpelada

13 Tipo de embarcación con capacidad de bodega que oscila entre $7 \mathrm{~m}^{3}$ y $12 \mathrm{~m}^{3}$.

14 En uno de los cambios de gabinete ministerial producidos este año, la licenciada Gladys Triveño fue reemplazada por Piero Ghezzi en el Ministerio de la Producción. 
en el Congreso de la República con el fin de que sustente y justifique la promulgación del Decreto Supremo citado, apelando a la Ley General de Pesca, Decreto Ley 25977, vigente desde el 21 de diciembre de 1992.

En el artículo 2 de la Ley General de Pesca del Decreto Ley N. $25977^{15}$. Es que se modifica ligeramente un punto concreto del D. S. 005-2012 y a la fecha está vigente pese al disgusto de los empresarios formales e industriales que capturan anchoveta para fabricar harina y a los cuales no se les permite incursionar en la franja de las 10 millas cercanas a la costa. Para los expertos en el tema, la gran cantidad de biomasa de anchoveta está cerca de las 10 millas de la costa, y ello acarrea el disgusto de los industriales que manejan embarcaciones de gran calado y cuya capacidad supera los $600 \mathrm{~m}^{3}$ o 600 toneladas de almacenamiento en bodega.

En estos casos, debería ser el Estado el que mediante sus instituciones y competencias debería intervenir en el mercado, regulando, vigilando y corrigiendo los fallos descritos líneas arriba. En el subsector de pesca marítima artesanal o de menor escala abunda la informalidad; además de crear sus propias reglas de juego, esta atenta contra la soberanía del consumidor por el desorden y la asimetría de la información; incluso, se pone en riesgo la calidad de vida del pescador, quien se aleja de la productividad y por ende no sale rápido del círculo de la pobreza que lo agobia a él y a su entorno familiar.

\section{SUGERENCIAS}

\subsection{De corto plazo}

- En el muy corto plazo, se debe proponer a las universidades privadas y públicas la realización de un mayor número de investigaciones en relación con el tema, que plantee al sector privado (mediante los gremios que lo representan) y al Gobierno Central una mejora en la infraestructura para el desembarque y preservación de las especies con estándares de calidad que garanticen un mercado ordenado, limpio y transparente.

15 Artículo 2. Son patrimonio de la Nación los recursos hidrobiológicos contenidos en las aguas jurisdiccionales del Perú. Es el Estado quien se encargará de regular el manejo integral y la explotación racional de los recursos por ser la pesca una actividad de interés nacional. 
- Proponer a cada región y a los gobiernos locales que si se instala o alberga un muelle artesanal o un lugar de desembarque tipo playa, se debe de respetar el ambiente y, de ser posible, fijar los límites de contaminación con multas o mecanismos disuasivos para evitar el deterioro del entorno.

- Es imperativo trabajar con las autoridades de los gobiernos regionales, locales, seguridad ciudadana, Policía Nacional del Perú y Marina de Guerra para desalojar de las zonas de desembarque a las personas de mal vivir, los mercados informales; además que se establezca el pago de multas por las infracciones y delitos ambientales.

- Fomentar la industrialización de más productos hidrobiológicos procesados (enlatados, congelados) para el mercado externo que cuenta con mayor poder adquisitivo.

\subsection{De largo plazo}

- Formalizar la mal llamada pesca marítima artesanal.

- Establecer una tipología adecuada para describir la pesca marítima para el consumo humano directo de mediana escala y que sea una unidad empresarial (embarcación) registrada en la Sunat, que tribute como toda empresa del ámbito formal.

- El Estado deberá establecer mecanismos y alianzas con el sector privado para capacitar a los actores o agentes vinculados con la actividad.

- En el proceso de formalización, establecer que el empresario registre en planillas a los peones que contrate como tripulantes y hacer que se cumplan todos los compromisos adquiridos por el trabajador de cada embarcación contratante.

- Proponer una ley con el fin de hacer prevalecer el cumplimiento del pago de un impuesto o cargos por tipos de contaminación (costos externos).

- Demandar la elaboración y puesta en debate de la Ley del Pescador, llamándola ya no de tipo artesanal, sino de mediana escala formal. 


\section{REFERENCIAS}

Banco Central de Reserva del Perú (BCRP). Estadísticas. Recuperado de http://www.bcrp.gob.pe/estadisticas.html

BCRP. (mayo de 2014). Notas de estudio del BCRP N. ${ }^{0}$ 32-33. Recuperado de http://www.bcrp.gob.pe/docs/publicaciones/notas estudios/2014

Dirección General de Capitanías y Guardacostas del Perú (Dicapi). Resultados del Censo Pesquero. Recuperado de 2014, de www.detrasdelacortina.com.pe/download/censo-pesquero-artesanal.pd

Instituto del Mar del Perú (Imarpe). Noticias. Recuperado de https:// www.google.com.pe/?gws_rd=ssl\#q=Imarpe+noticias\&tbm=nws

Instituto Nacional de Estadísticas e Informática (INEI) (2010). Anuario estadístico 2010. Recuperado de http://www.inei.gob.pe/estadisticas/indice-tematico/economia/

Instituto Nacional de Estadísticas e Informática (INEI) (2013). Anuario estadístico 2013. Recuperado de http://www.inei.gob.pe/estadisticas/ indice-tematico/economia/

Kleeberg, F., \& Rojas, M. (2012). Pesquería y acuicultura en el Perú. Lima: Universidad de Lima, Fondo Editorial.

Jiménez, B. (11 de abril 2013). El laberinto de la harina negra. La República. Recuperado de http://www.larepublica.pe/1104-2013/produccion-de-harina-de-pescado-el-laberinto-de-laharina-negra

Mamani, T. (2 de octubre 2011). Artesanales bolichitos fuera de borda respaldan ds-010-2010-Produce. Lo que Oanes no publica. Recuperado de http://loqueonnesnopublica.blogspot.com/2013/10/artesanales-bolichitos-fuera-de-borda.html

Ministerio de la Producción (Produce) (s. f.). Mapa del sitio. Recuperado de http://www.produce.gob.pe/index.php/mapa-del-sitio

Ministerio de la Producción (Produce) (s. f.). Primer Censo pesquero artesanal. Recuperado de http://www.produce.gob.pe/index.php/ estadisticas/censo-pesquero-artesanal

Morales, F. (2010). Proyecto de Ley del Pescador Artesanal (Paita). Recuperado de http:// www.slideshare.net/fmcslides/proyecto-deley-del-pescador-artesanal-paita 
OANNES (2011). "Señor de las olas". Recuperado de http:// www.OANNES.org.pe/OANNES-new_ver_2011/articulos_ columnistas.php

Ortiz, A. (31 de julio de 2010). Anepap: Mensaje del presidente Alan García evidencia el fracaso de su política pesquera artesanal. Pesca Artesanal. Recuperado de http://pescaartesanalenredperu. blogspot.com/2010/08/anepap-mensaje-del-presidente-alan.html

Soto, H. de (2000). The mystery of capital. Londres: Bantam Press \& Random House. 